\title{
Nasal Surgery in Adolescents and the Development of the Facial Middle Third: Conservative Surgery of the Dorsal Hump
}

\author{
Jose Juan Montes Bracchini* and Fabiana Cortés Acosta \\ Jose Juan Montes Bracchini* and Fabiana Cortés Acosta
}

Submission: July 30, 2018; Published: August 06, 2018

*Corresponding author: Jose Juan Montes Bracchini, Facial Plastic Surgery and Otorhinolaryngology, Private Practice, México, Phone: +5255318927, Email: jjuan_montes@me.com

\begin{abstract}
The objective of this article is to assess the importance of nasal surgery in adolescents and its impact in the middle facial third. Nasal surgery in this population tends to be performed just like in adults, as it is believed that it doesn't have much impact in the patient's nose development. However, it has been proved that the nose keeps on growing and still has an impact on the final outcome of the middle facial third. When this is not considered, an inappropriate corrective functional and aesthetic surgical technique might be selected, and as a result leave the patient with a suboptimal outcome. As the author dedicates the majority of his practice to nasal surgery, and has performed several in adolescents, noting how a well performed nasal surgery improves the normal aesthetics of the facial middle third, he would like to present a review of articles that outline this subject, as well as give his experienced opinion. This article will present a small review on the subject, to stimulate general otolaryngologists and residents so that they can comprehensively evaluate the younger patient with a nasal deviation. Hence giving them the tools to offer these patients the appropriate surgical management to treat their functional as well as the aesthetic alterations and thus avoid suboptimal outcomes that can leave the patient with further asymmetry of the facial middle third.
\end{abstract}

Keywords: Adolescents; Nasal Surgery; Facial Middle Third Development; Let-Down Technique

\section{Introduction}

The development of the nose has been studied in the past, in 1845 as described by Hilton [1], the vomer has a cardinal role in the downward and forward growth of the maxilla. Authors such as Fick and Landsberger have described in different animal models, how an alteration in the septal cartilage can lead to a shorter palate or a higher nasal cavity floor [2,3] described in a rabbit model how alteration to the septal cartilage resulted in poorly developed upper facial features (snout) which also affected the dentition (prognathism with lingual upper incisors) [4]. The nasal septum functions as a central axis which helps determine the correct forward and downward growth of the maxilla. It develops from the frontonasal and maxillary processes at week 4 to 8 of gestation [5]. The nasal growth centres, if disturbed can result in underdevelopment of the nose or a deviated septum, being the latter one the most common. Nasal breathing obstruction due to a deviated septum, enlarged turbinates or other less frequent disturbances, causes chronic oral breathing, which have an important impact in the development of the facial middle third, as it results in decreased maxillofacial muscle tone, narrowing of the maxilla, micrognathia, retrognathia and protrusion of the maxillary incisors, which result in a deficient and under-projected middle facial third [6]. Patients with nasal obstruction and dental malocclusion, have a deviated septum as they tend to have a high palate, consequence of constant oral breathing above mentioned. On the long run this reflects on the overall growth of the nose, which has more tension and a prominent dorsal hump.

The surgical correction of these deformities should be managed by a technique that can efficiently address them, from the deviated septum, nose and malar deficiency. The authors recommended technique to achieve this is the descent of the nasal pyramid, also known as the let-down technique. The let-down technique modified in 1975, is the combination of a septoplasty and a rhinoplasty by repositioning both the nasal septum and the nasal pyramid as it descends onto the facial plane without sinking furthermore, it preserves the integrity of the nasal dorsum, and the normal relation between the osteo-cartilaginous vault and lobular cartilages. It corrects the deviated septum and releases the nasal tension [7]. Hinderer's facial analysis draws a first line from the ala to the tragus and a second line from the lateral canthus to the commissure. The posterior and superior area from the convergence of these lines should be the most prominent part of the malar eminence [8]. A comprehensive evaluation of the nose, includes both the functional and aesthetic alterations and deformities (deviations, asymmetries) as well as the physiologic disturbances (collapsed 


\section{Global Journal of Otolaryngology}

nasal valve, deviated septum, enlarged turbinates) The facial analysis must determine the positive and negative characteristics in order to give an asserted diagnosis, which will therefore allow us to use the best surgical technique, that besides correcting the functional problem (deviated septum), can optimize the overall facial results needed in the adolescent patient.

\section{Discussion}

In the facial middle third, the malar region constitutes an anatomic area with a wide variety of shape and projection. The malar region can be divided in three areas, where the limits between one and other are barely perceptible: medial (paranasal), medial (malar) and lateral (zygomatic) From an aesthetic point of view, the malar eminence is very important as it provides the greater anterior projection and transverse dimension of the face (Figure 1) The appropriate development of this area gives a more harmonious oval shaped contour face, which is considered, aesthetically more pleasing. Furthermore, the malar region plays an important role in the more youthful look of the patient. Hence the overall diagnosis of the deviated nose must be considered within the facial context, taking attention to the malar eminence. Treatment must be individualized, with a comprehensive clinical and radiologic evaluation. The diagnosis must consider the deficiency in the bone structure as well as the soft tissue. In adolescents the malar eminence may be under-projected, with a deviated septum, leaving a tension nose deformity (Figure 2) The let-down technique has an additional benefit other than just restoring nasal function and aesthetics.

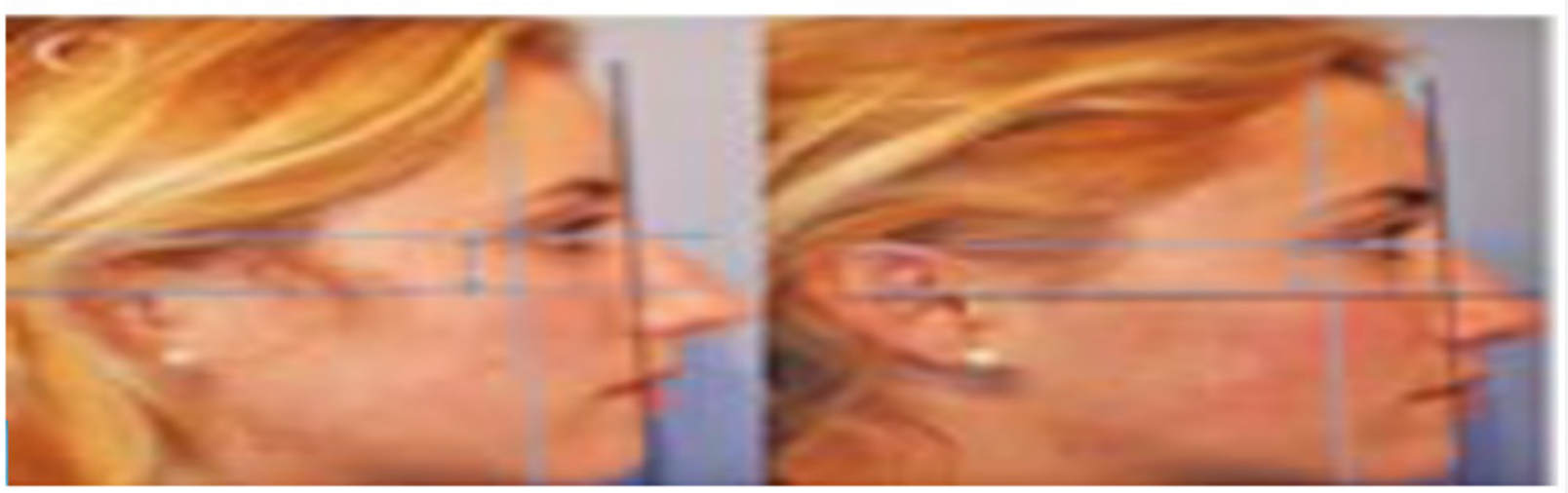

Figure 1: Preoperative and postoperative measurement of malar eminence to note correction of malar deficiency.

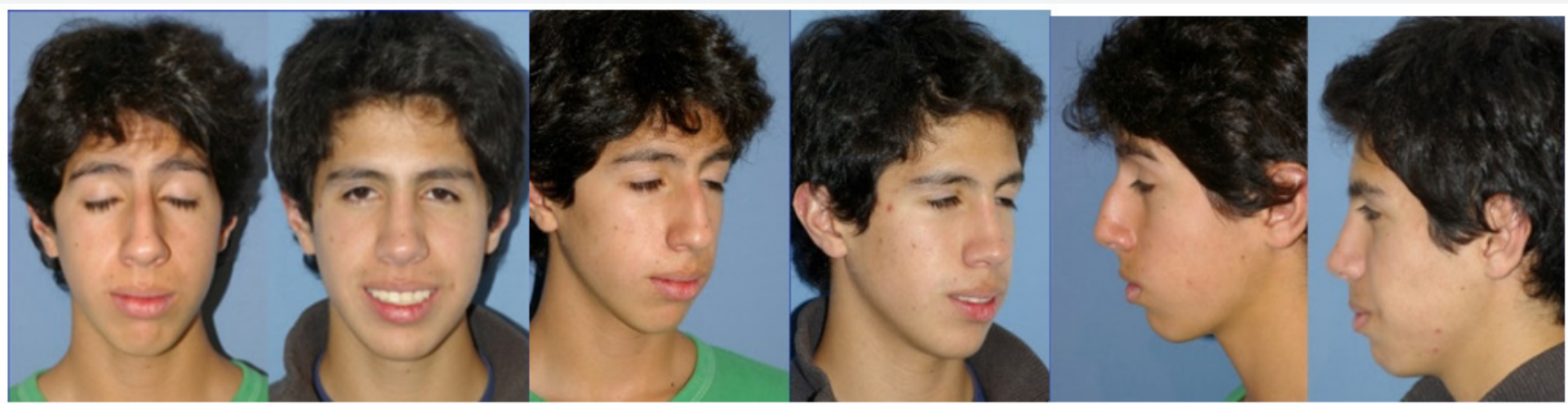

Figure 2: Patient 1. Preoperative photograph (left), postoperative photograph 1 year (right). The correction of the deviated nose and malar deficiency.

The advantages that performing a let-down offer are:

a) Being able to work with the nasal pyramid as a unit

b) Improvement of the facial middle third by increasing its contour without having to use implants or fillers, due to the mobilisation of the soft tissue overlaying the nasal pyramid as it descends;

c) It is the authors advised technique in patients were the aesthetic changes desired are complex (Figure 3).
This technique is also more useful in patients with nose tension deformity that have large dorsal humps, deviated septum and pyramid, since it works with these alterations as a unit, with its central component being the correction of the nasal septum. The improvement of the facial middle third is determined posteriorly by the displacement of the soft tissue adjacent to the nose, given by the descent of the nasal pyramid, this gives a filling effect to the deficient middle third, which brings better contour and balance to this area. 


\section{Global Journal of Otolaryngology}
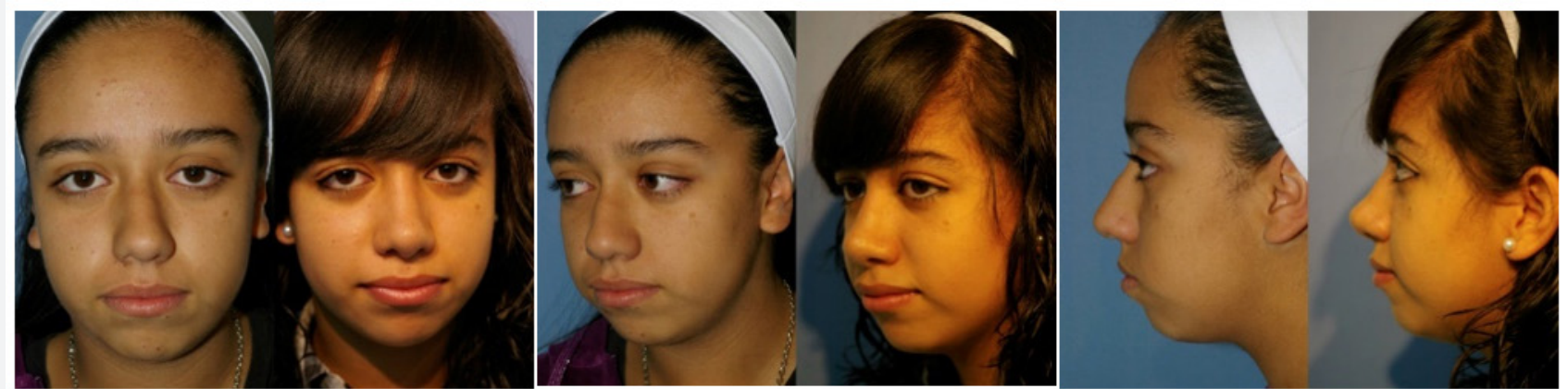

Figure 3: Patient 2. Preoperative photograph (left), postoperative photograph 1 year (right). The correction of the deviated nose and malar deficiency.

\section{Conclusion}

The influence of the displacement of the adjacent soft tissue to the nasal pyramid on the facial middle third after a rhinoplasty with let-down technique in adolescents, has a positive effect by filling in a natural way the deficient middle third of the face, giving the patient a more symmetric and balanced appearance. Adolescents with a nose tension deformity, frequently have malar deficiency. Nasal aesthetic surgery in this population has increased in popularity in the past years, however, there is little literature that addresses them in particular. Rhinoseptoplasty performed in adolescents should consider that they are undergoing a developmental stage, the technique used to correct the nasal deformity should address the overall facial context. Therefore, it is the authors suggestion to use the let-down technique in patients with nose tension deformity, dorsal hump and malar deficiency, as it provides the adequate correction for the mentioned alterations, presenting a better appearance of facial middle third in the adolescent.

\section{References}

1. Hilton J (1955) Rest and Pain ( $8^{\text {th }}$ edn.), XX Lippincott, Philadelphia 73(7): 569-572.

2. Fick L (1858) Uber die Ursachen der Knochenformen: Neue Untersuchungen. GH Wigand, Gottingen.

3. Landsberger R (1929) Die treibenden Krafte zur Dehnung und Streckung des Gesichtsschadels. Zahnarztl. Rdsch 38: 977-989.

4. Sarnat Bernard G (1970) Face and Jaws after Surgical Experimentation with the Septovomeral Region in Growing and Adult Rabbits 268: 1-30.

5. Eelam Adil, Goyal, Neerav, Fedok, Fred G (2014) Corrective Nasal Surgery in the Younger Patient. JAMA Facial Plast Surg 16(3): 176-182.

6. Linder Aronson S (1970) Adenoids: their effect on mode of breathing and nasal air flow and their relationship to characteristics of facial skeleton and the dentition: a biometric, rhino-manometric and cephalometric-radiographic study on children with and without adenoids. Acta Otolaryngol Suppl 265: 1-132.

7. López Ulloa Fausto (2011) Técnica del let down. Rhinoplasty Archive.

8. Larrabee WF, Makielski KH, Henderson JL (2004) Surgical anatomy of the face. $2^{\text {nd }}$ edn. Cheeks and Neck pp.175-180.

\section{Your next submission with Juniper Publishers will reach you the below assets}

- Quality Editorial service

- Swift Peer Review

- Reprints availability

- E-prints Service

- Manuscript Podcast for convenient understanding

- Global attainment for your research

- Manuscript accessibility in different formats ( Pdf, E-pub, Full Text, Audio)

- Unceasing customer service

Track the below URL for one-step submission https://juniperpublishers.com/online-submission.php 